\title{
PROPIEDAD DE LOS MEDIOS Y PRINCIPIOS DE INTERVENCIÓN DEL ESTADO PARA GARANTIZAR LA LIBERTAD DE EXPRESIÓN EN CHILE
}

\section{Pablo Ruiz-Tagle Vial*}

RESUMEN: Este trabajo se propone como objetivo estudiar la realidad actual de la propiedad sobre los medios de la comunicación y la libertad de expresión, discutir sobre la idoneidad de las acciones positivas del Estado para asegurar el acceso a la posibilidad de expresión de grupos excluidos del espacio público y analizar el desarrollo del "mercado de las ideas" en nuestro país.

PALABRAS CLAVE: Libertad de expresión - publicidad oficial del Estado - Ley $\mathrm{N}^{\circ} 19.733$ sobre Libertades de Opinión e Información y Ejercicio del Periodismo - principios de intervención del Estado en materia de libertad de expresión.

\section{MEDIA OWNERSHIP AND PRINCIPLES OF STATE INTERVENTION TO ENSURE FREEDOM OF EXPRESSION IN CHILE}

ABSTRACT: This paper aims to study the objective reality of the ownership of the means of communication and freedom of expression, to discuss the suitability of the positive actions of the State to ensure access to the possibility of expression of groups excluded from public space and analyze the development of the "marketplace of ideas" in our country.

KEY WORDS: Freedom of expression - the State advertising - Law No. 19.733 on Freedom of Opinion and Information and the Practice

* Abogado, Universidad de Chile, Magíster y Doctor en Derecho, Yale University. Profesor de Introducción al Derecho y Derecho Constitucional, Facultad de Derecho Universidad de Chile. La primera versión de este trabajo fue leída en la segunda jornada plenaria sobre el tema de la concentración de los medios en Chile organizado por el Centro de Derechos Humanos de la Facultad de Derecho de la Universidad de Chile el 20 de agosto 2008. También aprovecho de agradecer la investigación que ha servido como base de este trabajo de las ayudantes Paula Ahumada, María Jesús Fernández y Beatriz Hidalgo. Correo electrónico: pruiztagle@larrain.cl

Fecha de recepción: 19 de abril de 2011.

Fecha de aceptación: 26 de septiembre de 2011. 
of Journalism - Principles of State intervention about freedom of expression.

\section{1) Propiedad, Publicidad y Audiencia de los medios en Chile}

En el trabajo de los profesores de la Universidad de Chile, Osvaldo Corrales Jorquera y Juan Sandoval Moya, Concentración del Mercado de los Medios, Pluralismo y Libertad de expresión ${ }^{1}$, del ańo 2005, se muestra en detalle una radiografía de los medios en Chile que es necesario actualizar pero que contiene algunos de los rasgos principales que todavía hoy podemos reconocer respecto de los medios de comunicación en nuestro país.

\section{1) PRENSA ESCRita}

Para hacerse una idea de la concentración de la propiedad en materia de prensa escrita, basta decir que la empresa más antigua en esta materia tiene el control de 2 de los 8 diarios de circulación nacional, 1 de los 4 diarios zonales y 18 de lo 45 diarios regionales.

En materia de circulación y lectoría, el grupo de medios de prensa vinculados al grupo Edwards tenía a la fecha del estudio, un 51\% los días hábiles de la semana y un 58\% de lectoría los días domingos, relegando a COPESA a un segundo lugar con un $41 \%$, mientras La Nación se mantiene alrededor del $1 \%$. Más recientemente estos porcentajes de circulación han cambiado a favor de COPESA en los días de semana. En relación a la lectura de diarios, de un promedio equivalente de aproximadamente 1.404 .340 personas para los días de la semana, se aumenta hasta 2.034.376 personas durante los días domingo, lo que representa un incremento de aproximadamente un $45 \%$.

Según el estudio citado, la inversión publicitaria se distribuye en un 60\% para El Mercurio, un 19\% para COPESA, y el 29\% restante se distribuye entre los demás medios. Otro tema interesante de analizar, es el gran dinamismo de la inversión en el sector más bajo de la tabla (medios con menor participación en la inversión). La estructura que existe hoy en día de la prensa, se debe a la injerencia que ha tenido el Estado a lo largo de la historia.

Corrales J., Osvaldo y Sandoval M., Juan (2005) Concentración del Mercado de los Medios, Pluralismo y Libertad de expresión. Chile: ICEI, Universidad de Chile, pp. 1-22. Disponible en: http://www.comunicacion.uchile.cl/docs/corrales2005.pdf 


\section{2) TeleVisión}

Se puede apreciar la distribución de la inversión publicitaria en relación a los canales de televisión. Para 2004, se observa que tres canales concentran el $83 \%$ del total: UCTV con un 32,1\%, Megavisión con un $28,3 \%$ y TVN con un 22,6\%. Otras tendencias a destacar son el crecimiento de Megavisión y el decrecimiento de Chilevisión en el porcentaje de participación en la inversión publicitaria. Lo anterior muestra cómo el comportamiento de la inversión, similar a lo que vimos ocurría en los medios de prensa escrita, no responde necesariamente a un criterio de las audiencias que cada uno acapara. Esto queda en evidencia con TVN, que es el canal con más audiencia promedio, es el tercer canal en el cual más se invierte en publicidad. $\mathrm{O}$ con el caso de Megavisión, entidad que el año 2002 tenía una audiencia equivalente al 60\% de la de TV abierta y recibía el 30\% de la inversión versus el 27\% de la estación pública.

\section{3) RADIODIFUSIÓN}

Sobre la radiodifusión, conviene citar las palabras del representante de ARCHI, Luis Pardo, en el Informe Comisión Investigadora sobre Avisaje del Estado, que informan acerca del amplio espectro de radios existentes en el país, pero a su vez evidencian, también en este mercado, la disparidad en la distribución del avisaje comercial del Estado:

"...operan 1.856 radioemisoras, por lo que, dado el número de operadores, de unidades económicas, es la industria más dispersa y grande de Chile. Sin lugar a dudas, es el pais con mayor cantidad de emisoras por habitante. De las 1.856 que existen en el territorio nacional, 1.300 son de frecuencia modulada, 175 de amplitud modulada; la onda corta ya casi no se utiliza y hay varias emisoras que funcionan en la categoría de minima cobertura, que corresponde a las radios orientadas a funciones comunitarias.

Es importante resaltar que la mayoría de estas radioemisoras obtuvieron sus concesiones después de 1990, a través de un sistema de concurso público abierto, de acuerdo con lo que dispone la ley de telecomunicaciones aprobada bajo el imperio del régimen democrático, por lo que, en el caso de Chile, no es válida la aprensión en cuanto a que el espectro radioeléctrico se pueda distribuir según intereses de tipo político. Chile cuenta con una radio por cada diez mil habitantes, en tanto que el promedio latinoamericano es de una por cada 33 mil habitantes. Hay casos, como Brasil, donde hay una cada 60 mil, o Colombia, una cada 30 mil... A pesar de los elevados niveles de la radio respecto de la valoración ciudadana, la penetración y la audiencia, solo ha participado de un magro $8,2 \%$ de la inversión publicitaria, lo que se traduce en 33 mil millones de pesos. Incluso, este año por primera vez la vía pública le gana a la radio. Ese medio puede parecer muy eficiente en algunos aspectos, pero en términos del aporte al desarrollo social no tiene mayor significación... 
En el informe entregado por ChileCompra, se observa que dentro de la industria radial hay dos medios que concentran alrededor del $30 \%$ de la cartera del avisaje comercial del Estado: las radios Cooperativa y Biobio"2.

\section{2) EL MARCO JURÍdiCO DE LA LIBERTAD DE EXPRESIÓN EN CHILE}

La Ley de Prensa chilena ${ }^{3}$ define a los medios de comunicación social en su artículo $2^{\circ}$ como: "aquellos aptos para transmitir, divulgar, difundir o propagar, en forma estable y periódica, textos, sonidos o imágenes destinados al público, cualesquiera sea el soporte o instrumento utilizado". Estos medios constituyen un mercado especial, no solo porque el objeto mercancía es el de las ideas, sino porque para su subsistencia depende de dos "submercados": el de la difusión que comprende la circulación, el rating, la lectura, etc. y el de la publicidad o avisaje.

Los medios de comunicación que se usan hoy en día ${ }^{4}$ admiten una enorme diversidad y generan la ilusión que la conectividad y la comunicación entre los seres humanos es hoy más posible y robusta que antes.

Actualmente existe un alto nivel de concentración de los medios en cuanto se refiere al número de personas que detentan su propiedad, quienes se benefician con sus ingresos y también quienes controlan el público que accede a estos. Veamos lo que dicen algunos estudios que se han hecho en Chile sobre estas formas de concentración propietaria, publicitaria y de audiencia: "hasta los años 70 la estructura de propiedad de los medios de comunicación, especialmente la prensa, estaba vinculada a los partidos políticos. La dictadura de Pinochet implicó un control

2 “...el mercado de la prensa se encuentra fuertemente concentrado a nivel de la propiedad, los ingresos y los públicos. Ello se expresa en la posición dominante que han obtenido dos grandes empresas de carácter nacional, posición que se ha mantenido inalterada en las dos últimas décadas... (Además), la estructura de propiedad de las dos empresas dominantes ha sido estable en el tiempo (la concentración), ha contado con influencia estatal... el mercado de la prensa tiene un carácter oligopólico... los medios locales de prensa escrito no participan del proceso de concentración aquí descrito (a 2001)... no han entrado capitales extranjeros en la prensa escrita. Entre 1977 y1985 las radios FM se multiplican en más de siete veces mientras que las radios AM tienen un mínimo crecimiento. Por otro lado, las radios FM que en 1977 se encontraban altamente concentradas en la Region Metropolitana, tienen un fuerte crecimiento en las restantes regiones del país". Sunkel, Guillermo y Geofrroy, Esteban (2001). Concentración económica de los medios de comunicación. Chile: LOM Ediciones, pp. 50 a 52 y 59 .

3 Ley $\mathrm{N}^{\circ} 19.733$ Sobre Libertades de Opinión e Información y Ejercicio del Periodismo.

4 Junto a la prensa escrita, la radio y la televisión, el fax, el satélite y el cable han aparecido en estos últimos diez a quince ańos con una velocidad increíble nuevos medios de comunicación masivos. Entre ellos destaca el desarrollo de internet y de la telefonía móvil y sus productos y servicios derivados. El email, el messenger, las páginas web y los portales, los blog y los facebooks, los videos youtube y otras imágenes obtenidas por celular u otros medios digitales. Estos medios pueden dar la vuelta al mundo con sus informaciones en cuestión de segundos y parecen dejar obsoletas las formas de comunicación más tradicionales. 
ideológico sobre los medios de comunicación. A partir de la década de los 90 se asiste a un proceso de liberalización y privatización del sector infocomunicacional... (Hoy) los cuatro primeros operadores de cada una de las industrias analizadas (prensa, televisión abierta y cable, y telefonía que es la base de internet) alcanzan índices de concentración altamente significativos: ocurre con la prensa diaria, con la televisión abierta y de pago, con telefonía básica y móvil (e internet). La única excepción se encuentra, como ocurre también en otros países de la región, con la radio, que es la industria cultural con menor facturación" 5 .

Algunos estudiosos y una línea de jurisprudencia chilena, reconocen este factor de la concentración, pero ponen en duda si esta estructura de la propiedad, del avisaje y de los públicos en tan pocas manos, en verdad afecta la competencia entre los medios ${ }^{6}$. Otros estudios usan el argumento de la posibilidad de usar bienes públicos sucedáneos, por ejemplo reemplazar la radio AM por la FM o la televisión abierta por el cable, y estos criterios han fundado decisiones que han permitido nuevas acciones de concentración en la compra de estaciones de radio y televisión. Esta mirada económica de los efectos de la concentración me parece que es muy limitada porque no considera el derecho a la libertad de expresión como parte de un sistema que implica un concepto de ciudadanía y que se vincula con la calidad de nuestra democracia.

Estas ideas han inspirado a Cass Sunstein en sus libros Republic.com 7 donde ha expuesto una concepción ciudadana que valora el intercambio real entre personas diversas y desconfía de los mecanismos virtuales de internet para reproducir esa forma de interacción no manipulada. O dicho de otra manera, el uso intensivo de internet y de sus derivados tipo facebook, páginas web, blogs, wikis, messenger o medios de comunicación semejantes no aseguran el contacto con otras visiones de mundo y pueden llegar incluso a desvirtuar la noción más abierta e igualitaria que supone el proyecto ciudadano.

Recientemente, algunas personas (entre ellas Al Gore) han respondido que estas tecnologías de internet que Sunstein critica pueden ayudar a formar una ciudadanía más informada, pero todavía subsiste la objeción que alerta sobre la dificultad de deliberar usando las formas de las nuevas tecnologías. El ejercicio democrático supone la comparecencia en el espa-

\footnotetext{
5 Mastrini, Guillermo y Becerra, Martín (2006) Periodistas y Magnates: Estructura y concentración de las industrias culturales en América Latina. Argentina: Prometeo Ediciones, pp.150 y 170 .

6 Tribunal de Defensa de la Libre Competencia, Resolución N²0/2007 del 27 de julio de 2007. Ver también Dodns, Daniel (2011) Concentración de medios y libertad de comunicación. Un análisis jurídico-constitucional, memoria de prueba para optar al grado académico de Licenciado en Ciencias Jurídicas y Sociales, Facultad de Derecho de la Universidad de Chile. pp. 98-138.

7 Sunstein, Cass (2007) Republic.com 2.0. EE.UU.: Princeton University Press, pp. 1-272.
} 
cio público de proyectos de vida diversos, así como de distintas visiones que individual y colectivamente enriquecen la vida en sociedad de una manera no manipulada, con nombre y apellido, y no en forma anónima o impersonal como a veces se hace disponible la información en internet.

En Chile, el artículo 19 No 12 de la Constitución impone al Estado la obligación de garantizar el derecho de libertad de expresión en su doble aspecto de informar sin censura previa y de recibir información, tal como ha expuesto en sus decisiones el Tribunal Constitucional y la jurisprudencia de sus tribunales. Además, la ley $\mathrm{N}^{\circ} 19.733$ sobre libertad de opinión e información y ejercicio del periodismo, señala en su artículo $1^{\circ}$ que: "la libertad de emitir opinión y la de informar, sin censura previa, constituyen un derecho fundamental de todas las personas. Su ejercicio incluye no ser perseguido ni discriminado a causa de las propias opiniones, buscar y recibir informaciones, y difundirlas por cualquier medio, sin perjuicio de responder de los delitos y abusos que se cometan, en conformidad a la ley. Asimismo, comprende el derecho de toda persona natural o jurídica de fundar, editar, establecer, operar y mantener medios de comunicación social, sin otras condiciones que las señaladas por la ley. Se reconoce a las personas el derecho a ser informadas sobre los hechos de interés general"8.

Este mandato jurídico es puesto en duda porque como explican los profesores Sandoval y Corrales, en Chile existe de facto un "monopolio ideológico" que se expresa en las decisiones de los grandes avisadores y su alto nivel de uniformidad ideológica, que en lo económico se expresa en un alto nivel de compromiso con el modelo neoliberal y en lo cultural en un fuerte conservadurismo, de modo que cuando actúan como avisadores utilizan la inversión publicitaria como una herramienta para fortalecer a aquellos medios que les son más afines, introduciendo una distorsión en el mercado que dificulta la aparición de otras expresiones.

Por tanto, el Estado en Chile no solo debe actuar de forma negativa como abstención en materia de libertad de expresión al, por ejemplo, no censurar previamente los contenidos a ser difundidos, sino además debe actuar en forma positiva para asegurar el derecho de todas las personas a ser

$8 \quad$ El Estado tiene además el deber de proveer a los particulares de los medios necesarios para el desarrollo de la libertad de expresión y lo hace de acuerdo con la Constitución asegurando el derecho de fundar diarios, revistas y periódicos en los términos que seńale la Ley. Por tanto, en Chile la libertad de expresión se regula en la Constitución, el Pacto de Derechos de San José de Costa Rica, la ley sobre Libertades de Opinión e Información y Ejercicio del Periodismo $N^{\circ} 19.733$, el Código Civil y el Código Penal. Entre los proyectos de ley más relevantes que están pendientes en esta materia están los que se refieren al Estatuto del Periodista, al proyecto de ley que crea los servicios de Radiodifusión Comunitaria, el proyecto de ley que modifica el artículo 12 de la Constitución, y establece la naturaleza jurídica del espectro radioeléctrico, en conjunto con la televisión digital, el proyecto sobre neutralidad en la red, el proyecto de ley para delimitar el ámbito de la vida privada frente a la libertad de expresión, entre otras iniciativas, y la reforma constitucional del artículo octavo para asegurar la probidad de las candidaturas y el ejercicio de los cargos públicos. 
informadas sobre los hechos de interés general. Esta información es esencial para que los ciudadanos puedan ejercer sus derechos y conocer sus obligaciones.

\section{3) PRincipios de interVENCión Del Estado EN MATERIA DE LIBERTAD DE EXPRESIÓN}

Las formas de intervención que realiza el Estado en materia de libertad de expresión son múltiples, porque beneficia a algunos medios con su publicidad, porque los provee de información, y porque regula y afecta una serie de materias que son relevantes para el ejercicio de este derecho. La cuestión entonces es determinar si existen ciertos principios, normas o criterios jurídicos que justifiquen esta actividad interventora del Estado. Eso es lo que intentaré explicar en los párrafos que siguen:

1) El primer principio en torno al cual debe organizarse la actividad del Estado es la obligación de proteger la soberanía del consumidor y de garantizar de modo diferenciado la ciudadanía. Consumidores pueden ser incluso menores de edad o personas cuya voluntad e inteligencia está en formación y desarrollo. La ciudadanía implica una posición de igualdad en la esfera de lo público y supone el ejercicio de la deliberación, de la persuasión y de formas de racionalidad y comportamiento de personas maduras. El Estado debe proteger del fraude a los consumidores y contribuir a la formación ciudadana. Por ejemplo, desde el punto de vista de la construcción de ciudadanía no podemos creer que el pluralismo queda asegurado en el canal público de TVN al imponer un burdo sistema de cuoteo político en su directorio. La televisión pública chilena debe representar también a sus regiones, a los independientes, a los intelectuales, y a todos los grupos del sistema político. Esta tarea es perfectamente exigible al Estado como parte de sus obligaciones. La concepción ciudadana de la libertad de expresión también nos obliga a aceptar la idea que las personas que ocupan cargos públicos de elección popular no pueden tener intereses comprometidos en el control de los medios de comunicación social. Bobbio y Viroli explican en su libro Diálogo en Torno a la República $a^{9}$, los riesgos que supone aceptar a Berlusconi como Jefe del Gobierno si al mismo tiempo es propietario de medios que promueven su imagen y lo ayudan de forma desigual a participar en la esfera política. En Chile, el caso del candidato presidencial y lue-

\footnotetext{
9 Bobbio, Norberto y Viroli, Mauricio (2002) Diálogos En Torno a la República, Barcelona:
} Editorial Tusquets, pp. 1-128. 
go elegido presidente Sebastián Piñera, quien ha sido propietario de una estación de TV abierta, justifica la reforma constitucional que se ha propuesto respecto del artículo 8 para obligarlo a transferir su propiedad al momento de ser candidato para ocupar un cargo público y no esperar que dicha transferencia se realice una vez elegido. El neoliberalismo también se expresa en el deterioro de los espacios públicos porque no cree en la experiencia enriquecedora de la ciudadanía. Por eso, otra forma activa en la cual el Estado puede ayudar a construir ciudadanía consiste en utilizar la publicidad oficial y otros medios e incentivos para que las personas, particularmente los jóvenes, se inscriban en los registros electorales. La concepción ciudadana de la libertad de expresión también supone hacer cumplir la ley sobre los bienes nacionales de uso público y terminar con esta abusiva utilización de nuestras plazas, caminos y lugares públicos. La vinculación de alcaldes, funcionarios públicos, parlamentarios y políticos con las empresas de publicidad es patológica. Por suerte el Consejo de Defensa del Estado, la Contraloría, el Tribunal Electoral, los tribunales ordinarios y la opinión pública están reaccionando frente a estas formas de abusivas. Por supuesto que este control ciudadano y la lógica de la protección de los consumidores, debe extenderse a la transparencia sobre los gastos en publicidad de las universidades, que en Chile integran el grupo de los grandes avisadores. La obligación de transparentar sus ingresos en la modalidad FECU y el control más efectivo de los subsidios educacionales puede llegar a impedir un consumismo fraudulento y un deterioro de los ideales y prácticas ciudadanas.

2) El segundo principio es la protección de los más débiles, de los menos aventajados, de los niños, de las mujeres pobres, de los líderes sindicales, de los marginados que muchas veces no salen en los medios o peor aún que son denigrados, asociando sus personas, sus demandas y sus características a situaciones de violencia, de agresión. En esta línea debe promoverse la expresión tranquila de estos grupos en los medios. Una medida en este sentido podría consistir en dar financiamiento público a un sistema de medición de audiencia pública de la televisión que se instale en regiones y que mida las preferencias de los grupos E y otros que no están representados como corresponde en el "people meter". Otra medida que vengo sosteniendo desde 1995 es regular la exposición de los menores a las tandas publicitarias en los horarios de televisión infantil. La Children's Television Act de 1990 de EE.UU. ha permitido solo hasta un máximo de 10.5 minutos de publicidad por cada hora de televisión en días de semana, y hasta 12 en los días de fin de semana para los horarios infantiles.

3) El tercer principio consiste en pensar que la libertad de expresión no existe en el vacío, sino que es parte de un sistema democrático que 
debe asegurar y fomentar un debate público robusto. Esta concepción de la libertad de expresión expuesta por Owen Fiss ${ }^{10}$ advierte que el derecho a la libre expresión puede ser amenazado, tanto por el Estado, como también por personas privadas. Se trata de un nuevo modelo de la libertad de expresión que lo vincula al robustecimiento de la democracia. En este sentido, Cass Sunstein en su libro Republic. com señala que el Estado debe proveer acceso no a los lugares donde se produce la libertad de expresión, sean estos plazas o parques, sino también a las personas que buscan recibir esa información. La libertad de expresión permite que los ciudadanos se comuniquen con sus representantes y ejerzan el control del poder, y por eso Stuart Mill llamó a la opinión pública el cuarto poder del Estado. La deliberación entre individuos racionales asegura un efectivo autogobierno y no solo se logra con mayor educación, sino que con una adecuada información. Así por ejemplo, se justifican la imposición de la franja electoral en los canales de televisión, las exigencias de nacionalidad o de presencia local respecto de los propietarios y directores de los medios de comunicación, el otorgamiento de licencias, la garantía del derecho a réplica cuando se es aludido en los medios y buena parte de las demás regulaciones legales que existen respecto de esta actividad y que el Estado debe hacer cumplir de manera activa ${ }^{11}$.

4) El cuarto principio es el de la responsabilidad. Este principio caracteriza a todas las sociedades civilizadas, y en materia de la libertad de expresión supone que no podemos dar un cheque en blanco a que los que ejercen este derecho en los medios, sean sus propietarios, periodistas o el público. Este principio acepta la idea de terminar con la censura previa, porque no puede haber responsabilidad si hay censura, pero al mismo tiempo se compromete con establecer normas jurídicas para que todos aquellos que producen daños, de cualquier naturaleza que sea este daño, asuman su responsabili-

$10 \quad$ Fiss, Owen (1986) "Free Speech and Social Structure", en Iowa Law Review, No 71, pp. $1405-1425$

11 Por ejemplo, nuestra regulación actual es más amplia en cuanto a la propiedad de los medios de comunicación, ya que elimina la restricción de acceso de extranjeros a la propiedad de los medios, estableciéndose requisitos de domicilio en Chile y nacionalidad chilena solo a sus presidentes y representantes legales. En cuanto al mercado de las radioemisoras, se establece además el principio de reciprocidad, ya que en caso de propiedad extranjera de más de un $10 \%$ se exige que se acredite que en el país de origen a los chilenos les sean otorgados derechos similares. El principio de reciprocidad es expresión del sistema democrático y globalizado en el que funcionan los medios. Por eso, tal como lo he expresado, es criticable la posición de algunos canales chilenos de televisión abierta que en su oportunidad impugnaron ante los tribunales la franja electoral porque plantearon que el derecho a la libertad de expresión era un simple derecho de concesión autónomo. Responden a un concepto democrático los fallos de los tribunales y del Tribunal Constitucional que rechazaron esa posición en nombre de la libertad de expresión. 
$\operatorname{dad}^{12}$. La censura que existió en materia cinematográfica, y la censura judicial que existió en nuestro país a nivel constitucional fue reforzada a nivel constitucional por Jorge Alessandri y Jaime Guzmán ${ }^{13}$ y se impuso en nombre de la protección de la honra y la vida privada y terminó con el caso de la Tentación de Cristo. A pesar de nuestros progresos, hemos pasado desde un sistema muy deficiente a otro que no alcanza a ser bueno, porque en los últimos ańos a pesar de nuestra derogación de la censura, no hemos podido establecer sistemas eficientes de responsabilidad de los medios cuando producen daños en las personas.

5) El quinto principio es el de la primacía del derecho sobre otras formas de regulación. Este principio es propio de las sociedades abiertas porque las personas resuelven sus conflictos por medio del derecho, precisamente porque no necesariamente comparten los mismos estándares morales, éticos, económicos o políticos ${ }^{14}$. El rol del Estado en este caso, es asegurar de modo activo el funcionamiento de los

12 El daño que puede producirse en el ejercicio de la libertad de expresión puede consistir en la afectación de un derecho constitucional. Esto es precisamente lo que se produce en los conflictos de la libertad de expresión con la honra y la vida privada. El daño puede también tener una connotación penal, como en los casos en que se afecta el bien jurídico que se protege en el delito de injurias, calumnias o en las formas delictivas de intromisión ilegítima, y por supuesto, las formas de daño también pueden asumir las hipótesis de responsabilidad civil extracontractual o contractual de acuerdo a las reglas generales. Por eso cuando se habla de responsabilidad por el ejercicio de la libertad de expresión se debe hablar de un sistema que comprende aspectos constitucionales, penales, civiles, de legislación común y especial. En Chile no hemos sido responsables en el ejercicio de la libertad de expresión, porque tuvimos un sistema muy deficiente que consistió en la censura constitucional previa combinada con la irresponsabilidad jurídica en materias de este derecho, porque prácticamente no había casos de responsabilidad penal ni civil en que efectivamente se responsabilizara a los que abusaban de la libertad de expresión.

13 Ver al respecto Evans, Enrique (1999) Los Derechos Constitucionales. 2a Ed., Santiago: Editorial Jurídica de Chile, Tomo I, pp. 220-234 y Tomo II, pp. 26-104.

14 En el caso de la libertad de expresión este principio tiene mucha importancia, porque tal como he explicado en un trabajo que escribí en 1995 y que titulé "Apuntes sobre la Libertad de Expresión y la Censura en Chile", en Chile coexisten muchos entes que regulan e intervienen de manera simultánea en el ejercicio de la libertad de expresión. Entre tanto ente paralelo muchas veces hemos extraviado la idea republicana fundamental, según la cual en una sociedad civilizada democrática, deben ser los tribunales y el derecho común que emana del parlamento la forma que debemos preferir para solucionar conflictos. Si resulta en cambio que el CONAR, la ANATEL, la ARCHI, el Consejo de Calificación Cinematográfica, el Consejo Nacional de Televisión, el Consejo de Ética del Colegio de Periodistas, el Consejo de la Federación de Medios y tantos otros entes, producen sus propias reglas y desplazan al derecho y a los tribunales como sistemas de resolución conflictos, caemos en una lógica de estamentos, de feudalismo regulatorio que perjudica la calidad de nuestra democracia. El estamento o los feudos en este caso lo forman los periodistas o los propietarios de medios o quienes comparten una misma visión de esta actividad, que a veces la validan por medio de autorregulación pero no siempre justifican sus criterios frente a los demás ciudadanos chilenos. Ver Ruiz-TAgle, Pablo (2002). "Apuntes sobre libertad de expresión y censura en Chile". En: Derecho, Justicia y Libertad, México D.F.: Ediciones Fontamara, pp. 139-174. 
tribunales y de los organismos públicos que controlan la libertad de expresión para que estos no sean capturados por la fuerza de los intereses particulares y para que aseguren un sistema de protección de los derechos ciudadanos y de los valores democráticos.

6) El sexto principio se refiere al control y la transparencia del avisaje público o publicidad del gobierno ${ }^{15}$. Según hacen notar algunos, esta publicidad representa menos del 5\% del total del gasto en publicidad en Chile ${ }^{16}$. Sin embargo, los problemas que se presentan al respecto se refieren, en primer término, a la definición y los objetivos que justifican la publicidad oficial o estatal, respecto de la cual no hay claridad $^{17}$. En segundo lugar, al problema de la elección de los medios de comunicación donde se publica. Ejemplo de esto es que El Mercurio recibe cerca del 50\% del avisaje de Corfo, Conaf y Fonasa, que son servicios públicos cuyos beneficiarios muchas veces no se encuentran dentro del público objetivo que lee este medio ${ }^{18}$. En tercer lugar, existen criterios poco claros que se utilizan en los convenios marcos a través de Chilecompra por falta de transparencia ${ }^{19}$ en el proceso de

15 El año 2005, el Estado gastó en publicidad \$6.413.156.000 en televisión y \$4.315.023.000 en prensa, tomando en cuenta al Gobierno, ministerios, municipalidades, servicios e instituciones del Estado, de acuerdo al Informe de la Comisión Especial Investigadora sobre avisaje del Estado, p. 1. Hay empresas del Estado que no se incluyen en esta cifra, y también es importante tener en cuenta la cantidad mencionada.

16 Información entregada por Pro Acceso (Moisés Sánchez) y citada en el Informe de la Comisión Especial Investigadora sobre avisaje del Estado de la H. Cámara de Diputados: El gasto público en publicidad oficial en relación con la inversión total publicitaria es bastante bajo. Se han mencionado cifras cercanas al 5\% de la torta en general, lo que significa que es una cifra bastante pequeña en comparación con el gasto total. No obstante, para los medios más pequeños, con pertinencia local o regional, que tienen economias bastante básicas y sistemas de contratación de personal referidos a una cantidad muy menor-que no superan las cinco, dos o, a veces, una persona-, el acceso a estos recursos constituye, dentro de su propia estructura económica, un aspecto importante para su sostenibilidad financiera. Disponible en: http://www.camara.cl/pdf. aspx?prmID=59\&prmTIPO=INVESTIGAFIN p.30.

17 Sobre el primer problema, es necesario que se aclare y defina lo que se va a entender por publicidad oficial para que, de este modo, los recursos que por ley deben destinarse a este fin lo hagan realmente y no se utilice ese dinero con otros fines en nombre de la "publicidad oficial". Al respecto es necesario precisar que el objetivo de la publicidad oficial debe ser informar, debe ser un servicio para los ciudadanos y no para que el Gobierno de turno se haga propaganda, ni busque posicionarse en la opinión pública. Hoy vemos que esto no se cumple, pues no es poco común encontrar, por ejemplo, publicidad del Ministerio de Obras Públicas mostrando todo tipo de obras que ha realizado a lo largo del país, que pareciera querer algo más que informar.

18 Informe de la Comisión Especial Investigadora sobre avisaje del Estado, p.1.

19 La falta de transparencia con que se asignan los recursos. Al respecto, la información que existe es muy difícil de conseguir, confusa y poco sistemática, en gran parte por el manejo de la publicidad oficial, la cual es asignada por cada ministerio e institución del Estado, con independencia unas de otras. El problema no se acaba acá, ya que además existe información reciente sobre irregularidades en el proceso de venta de publicidad al gobierno. Al respecto, los encargados de vender publicidad al gobierno, de la región de Valparaíso, han señalado que funcionarios negocian con ellos directamente el contrato y luego abren el pro- 
contratar con los medios; y por último, existe la concentración que hay del avisaje estatal en determinados medios de comunicación. Es discutible si usar la publicidad oficial a modo de subsidio de los pequeños medios de comunicación que están en constante lucha por subsistir, por ejemplo para avisar en radios comunitarias o prensa local. Pareciera que la respuesta que debe darse a esta interrogante es negativa, ya que la publicidad oficial debe llegar a su público objetivo, y no debe usarse con otros fines que no sea informar a quienes corresponde la información que se quiere transmitir. Si al público se llega mediante radios comunitarias o prensa local entonces está justificada, pero incorporar otros criterios para la elección de los medios de comunicación, solo incrementará más el problema ya existente sobre lo poco profesional que resulta la compra de publicidad por parte del Estado. Además, la decisión sobre esta forma de subsidio, debe hacerse de manera no arbitraria y por medio de criterios que se expresen con claridad en una ley según exige el artículo 19 No 22 de nuestra carta fundamental.

\section{A MODO DE CONCLUSIÓN}

En definitiva, los principios de protección de los consumidores y de garantizar la ciudadanía, protección de los débiles y los marginados, promoción de un debate público democrático robusto, responsabilidad, primacía del Derecho y control y transparencia del gasto en publicidad oficial, justifican una intervención más activa del Estado. En muchas de estas materias no existe acuerdo en la ciudadanía chilena, pero en lo que están todos los sectores de acuerdo es en realizar más estudios para informarnos mejor sobre la realidad de la libertad de expresión en nuestro país y a eso esperamos haber contribuido con estos comentarios.

\section{BIBLIOGRAFÍA}

Asociación por los Derechos Civiles (2008) El precio del silencio: Abuso de publicidad oficial y otras formas de censura indirecta en América Latina. Buenos Aires: Asociación por los Derechos Civiles; New York: Open Society Institute.

ceso de licitación utilizando el sistema de Chilecompra, de modo que los resultados ya han sido arreglados de antemano. Asociación por los Derechos Civiles (2008) El precio del silencio: Abuso de publicidad oficial y otras formas de censura indirecta en América Latina. Buenos Aires: Asociación por los Derechos Civiles; New York: Open Society Institute, p. 51. 
Bовbio, Norberto y Viroli, Mauricio (2002) Diálogos en Torno a La República, Barcelona: Editorial Tusquets.

Corrales J., Osvaldo y Sandoval M., Juan (2005) Concentración del Mercado de los Medios, Pluralismo y Libertad de expresión. Chile: ICEI, Universidad de Chile, pp. 1-22. Disponible en: http://www. comunicacion.uchile.cl/docs/corrales2005.pdf

Dodns, Daniel (2011) Concentración de medios y libertad de comunicación. Un análisis jurídico-constitucional, memoria de prueba para optar al grado académico de Licenciado en Ciencias Jurídicas y Sociales, Facultad de Derecho de la Universidad de Chile (sin publicar).

Evans, Enrique (1999) Los Derechos Constitucionales. 2a Ed., Santiago: Editorial Jurídica de Chile, Tomos I y II.

Fiss, Owen (1986) "Free Speech And Social Structure", en Iowa Law Review, No 71.

Mastrini, Guillermo y Becerra, Martín (2006) Periodistas y Magnates: Estructura y concentración de las industrias culturales en América Latina. Argentina: Prometeo Ediciones.

Ruiz-Tagle, Pablo (2002). "Apuntes sobre libertad de expresión y censura en Chile". En: Derecho, Justicia y Libertad, México D.F.: Ediciones Fontamara.

Sunkel, Guillermo y Geoffroy, Esteban (2001) Concentración económica de los medios de comunicación. Chile: LOM Ediciones.

Sunstein, Cass (2007) Republic.com 2.0. EE.UU.: Princeton University Press. 